\title{
Vajinismus tanılı kadınların desteklenmesinde ebelerin rolü
}

\author{
Midwives role in supporting women with vaginismus diagnosis
}

\author{
Esma Demirezen®, Zeynep Dilșah Karaçam²®
}

\section{öz}

Cinsel sağlığa ilişkin sorunlar kadınların sadece cinsellikten uzak durmasına değil tüm yaşam kalitesini olumsuz yönde etkilemektedir. Kadın cinsel işlev bozuklukları arasında vajinismus yaygınlığı ve etkinliği açısından önemli bir yere sahiptir. Ebeler her yaştan kadına birinci ve ikinci basamak sağlık merkezlerinde kadın sağlığı ve hastalıkları, gebelik öncesi, gebelik döneminde, gebelik sonrası dönemde en fazla ulaşan sağlık profesyonelleri arasındadır. Ebeler bakım verici rolleri dıșında, eğitimci, danıșman, savunucu, araştırıcı, vaka yöneticisi rolleri kapsamında kadınlara her aşamada destek olmaktadırlar. Bu roller "Kadın Cinsel Sağlığı" odağında da ayrı bir öneme sahiptir. Ülkemiz gibi gelenekselliğini önemli ölçüde koruyan, kadın cinselliğinin rahat ifade edilmediği toplumlarda ebelerin konunun tıbbi, sosyal ve psikolojik boyutuna hâkim olması büyük önem taşımaktadır. Özellikle konu ile ilgili eğitim, danışmanlık ile bilgilendirme, bilinç oluşturma, uygun merkezlere yönlendirme çalışmaları, tanı sonrası takip ve tedavi sürecinde eğitim, danışmanlık, vaka yönetimi destek hizmetlerinde ebeler kadın cinsel sağlığı çalışmaları kapsamında önemli bir yere sahiptir. Ebelik uygulamaları sanılanın aksine sadece gebelik, doğum ve aile planlaması hizmetleri ile sınırlı değildir, kadın sağlığının tüm boyutları ile ilgilidir. Kadın sağlığına geniş bir bakış açısı ile ebelerin de "Kadın Cinsel Sağlığı” kapsamındaki rol ve sorumluluklarının bilincinde olmaları büyük önem taşımaktadır. Ancak konuyla ilgili yönlendirici çalışmalar ülkemizde sınırlıdır. Bu derlemenin amacı ülkemizde kadın cinsel işlev bozuklukları arasında \%50 gibi önemli bir yere sahip vajinismus sorunu kapsamında ebelerin rol ve fonksiyonlarına dikkat çekmek ve vajinismus tanılı kadınların tedavi sürecinde profesyonel destek alanlarını ön plana çıkarmaktır. Bu bilgilerin ebelerin kadın sağlığını cinsellik boyutu ile birlikte ele almaların önemini vurgulama ve bu kapsamdaki profesyonel uygulamalarına ışı tutacağı düşünülmektedir.

Anahtar Kelimeler: cinsellik, ebe, kadın cinsel sağlığı, kadın cinsel işlev bozukluğu, vajinismus

\section{ABSTRACT}

Problems related to sexual health not only negatively affect women's abstinence from sexuality but also their entire quality of life. Midwives are in perfect position to reach women of all ages in primary and secondary health centers, gynecological health and diseases, prepregnancy, pregnancy period, and post-partum period. Midwives have responsibilities as caregiver roles, educator, consultant, advocate, researcher, case manager, they support women at every stage. These roles have a special importance in the focus of "Women's Sexual Health". It is of great importance that midwives have a command of the medical, social and psychological aspects of female dysfuntion problems espacially in societies such as our where female sexuality is not easily expressed. Midwives have an important place in sexual health education, informing with counseling, raising awareness, refering to appropriate centers, training for follow-up and treatment after diagnosis, and case management services. Midwifery practices are not only limited with pregnancy, birth and family planning services. With a broad perspective on women's health, it is of great importance for midwives to be aware of their roles and responsibilities within the scope of "Women's Sexual Health". However, directive studies on the subject are limited in our country. The aim of this review is to draw attention to the roles and functions of midwives under the problem of vaginismus, which has an important place in female sexual presentation in our country, like $50 \%$, and to highlight professional support areas that will be the treatment for vaginismus. These imformations will emphasize the importance of addressing women's health together with the sexuality dimension and will keep it in scope of their midwifery professional practices.

Keywords: sexuality, midwife, female sexual health, female sexual dysfunction, vaginismus
'İstanbul Üniversitesi-Cerrahpaşa, Sağlık Bilimleri Fakültesi, Ebelik Bölümü, Istanbul, Türkiye

${ }^{2}$ Başakşehir Çam ve Sakura Şehir Hastanesi, İstanbul, Türkiye

\section{Yazıșma Adresi/ Correspondence:}

Dr. Öğr. Üyesi Esma Demirezen

İstanbul Üniversitesi- Cerrahpaşa, Sağlık Bilimleri Fakültesi, Ebelik Bölümü, İstanbul, Türkiye

Tel: +90 212-8663700/43164

E-mail: esma.demirezen@istanbul.edu.tr

\section{GíRiș}

İnsan yaşamının önemli bir parçası olan cinsellik; iyilik halini, sağlığı sürdürmede yaşamsal rol oynar. ${ }^{[1]}$ Cinsel sağlık, çiftlerin yaşamlarında, genel sağlık durumlarını, zihinsel sağlıklarını ve yaşam kalitelerini etkilenmesinde önemli bir rol oynayan faktörlerden biridir. ${ }^{[2,3]}$ Cinsel sağllğa ilişkin sorunlar birçok kadını cinsel ilişkiden uzaklaştırmak ile birlikte yaşam kalitesini de olumsuz yönde etkilemektedir. Kronikleşen bu sorun zaman içerisinde bireysel bir sorun olmaktan çıkar ve çiftin evlilik yaşantısını da olumsuz etkilemektedir. ${ }^{[4]}$ 
Kadın cinsel işlev bozuklukları arasında vajinismus ilk sırada yer almaktadır. Ülkemizde ebeler birinci ve ikinci basamak sağlık merkezlerinde her yaştan kadına ulaşan sağlık profesyonelleri olarak üreme sağlığı konuları dışında kadın cinsel sağlığı konusunda da her sosyoekonomik düzeydeki kadına ulaşma konusunda önemli bir konuma sahiptir. Bu derlemenin amacı vajinismus tanılı kadınların desteklenmesinde profesyonel ebelerin rol ve fonksiyonlarını ortaya koymaktır. Birinci, ikinci basamakta farklı birimlerde her yaştan kadına ulaşan ebelerin vajinismus tanısı almış kadınları izlenmesi konusunda rolleri ve fonksiyonları konusunda farkında olmaları büyük önem taşımaktadır.

\section{KADIN CINSEL IȘLEV BOZUKLUKLARI VE SINIFLANDIRILMASI}

Cinsel işlev yaşamın vazgeçilmez bir parçasıdır. Bu nedenle cinsel işlev bozukluğu, bir bireyin refahı üzerinde olumsuz bir etki yaratabilir. ${ }^{\left[{ }^{[}\right]}$Kadın cinsel işlev bozukluğu cinsel yanıt döngüsünün evrelerindeki (istek, uyarılma, orgazm ve çözülme) fizyolojik süreçlerden birinde ya da bir kaçın da açığa çıkan bozulma olmakla birlikte kadınların yaşam kalitesini düşüren vasküler, nörojenik, hormonal, müsküler ve farmakolojik etkileri olan çok yönlü bozulmalar olarak da tanımlanmaktadır. ${ }^{[6]}$ Öksüz ve Malhan (2006) yapmış oldukları çalışma da kadınlarda cinsel disfonksiyon sıklığının ortalama $\% 48,3$ olduğunu, cinsel disfonksiyon yaşayan kadınların \%35,9'unun uyarılma bozukluğu, $\% 40,9$ 'unun islanma problemleri, \%42,7'sinin orgazm bozukluğu, \%45'inin doyumsuzluk, \%42,9'unun ağrı bozuklukları yaşadığı sonucuna ulaşmışlardır. ${ }^{[6]}$

Ülkemizde CETAD tarafından yapılan araştırmada \%3060'ında yaşamları boyunca en az bir cinsel sorun yaşadığı belirlenmiştir ve yardım almak için başvuran kadınlarda önde gelen yakınmanın vajinismus olduğu saptanmıştır. ${ }^{[7]}$

Kadın Cinsel Fonksiyon Bozukluğu'da benzer şekilde tanımlanmakta olup Diagnostic and Statistical Manual of Mental Disorders (DSM) IV ve V versiyonlarında Tablo 1 'de görülen şekilde sınıflandırılmaktadır. ${ }^{[8,9]}$

\section{VAJINISMUSUN TANIMI VE SINIFLANDIRILMASI}

Vajinismus, ilk olarak 19. yüzyılda Amerikalı Jinekolog Sims tarafindan "artan fizyolojik uyarılma ile beraber vajinal sfinkterin spazmodik kasılması” şeklinde tanımlanmıştır. "Kişisel gözlemlerime dayanarak, evlilik anlaşmasının her iki tarafına da böylesine bir mutsuzluk yaşatan ve yine bu kadar kolay, kesin ve güvenli biçimde tedavi edilebilen başka bir hastalık olmadığını ifade etmek isterim” diyerek vajinismus
Tablo 1. DSM-IV ve DSM-V'e göre kadın cinsel fonksiyon bozukluğu sınıflandırması

\begin{tabular}{lc}
\hline DSM-IV & $D S M-V$ \\
\hline Hipoaktif cinsel istek bozukluğu & \\
Öznel cinsel uyarılma bozukluğu & \\
$\begin{array}{l}\text { Genital cinsel uyarılma bozukluğu } \\
\text { Kombine genital-öznel uyarılma bozukluğu } \\
\text { Israrlı cinsel uyarılma bozukluğu }\end{array}$ & Cinsel istek/ \\
\hline Kadın orgazm bozukluğu & \\
& Kadılı orgazm \\
\hline Disparoni & bozukluğu \\
Vajinismus & Genitopelvik \\
Cinsellikten tiksinti duyma bozukluğu & ağrı/ penetrasyon \\
\hline
\end{tabular}

hakkındaki görüşlerini dile getirmiştir. ${ }^{[10]}$ Vajinismus (L. vajina: kılıf; -ismus: eylem, edim); vajen girişindeki kasların spazmı sonucu cinsel birleşmenin mümkün olmadığı ya da son derece ağrılı bir kas bozukluğu olduğu, bu kasılmayla beraber tüm bedenin kasılması, bacakların kapanması, korku, kaçınma tepkisi ve vajinal girişin olamayacağ inancında eşlik etmesidir. Vajinal spazm çoğunlukla cinsel birleşme ile sınırlı kalmaz; tampon kullanımında ve jinekolojik muayene sırasında da gözlendiği bilinmektedir. Kadının kasılan kaslar üzerinde hiçbir kontrolü olmadığını düşünmesi nedeniyle cinsel işlev bozuklukları arasında kadını en çaresiz bırakan bozukluğun vajinismus olduğu bilinmektedir. [11,12] Amerikan Psikiyatri Birliği'nin (American Psychiatric Association, APA) yayınladığı DSM IV-TR'da vajinismus, primer ve sekonder olarak sınıflandırılmıştır. Primer vajinismus, kadın cinsel hayatının başladığı andan itibaren hiçbir şekilde cinsel ilişkiye girememesi olarak tanımlanmaktadır. Sekonder vajinismus ise daha önceden vajinal ilişkiye sorunsuz girebilen bir kadının, travmatik bir olay sonrası yaşadığı istem dışı kasılmalar olarak tanımlanmaktadır. Kadın cinsel işlev bozuklukları arasında en fazla primer vajinismus görülmektedir. ${ }^{[8,13-15]}$ APA 2013 yılında ise DSM-5'i yayınlamıştır ve DSM-5'te DSM IV-TR'deki "cinsel ağrı bozuklukları" başlığı ve bu başlıktaki vajinismus ve disparoni tanımları kaldırılmıştır ve iki tanıyı da içine alan "cinsel organlarda-pelviste ağrı/içe girme bozukluğu” olarak tanımlanmıştır. Bu bozukluk oluşturduğu sıkıntının derecesine göre "ağır olmayan", "orta derecede" ve "ağır" olarak üç alt tipe ayrılmıştır. ${ }^{[9]}$

Buna göre DSM-5'te bu bozukluğun tanı kriterleri şöyle sıralanmaktadır:

\section{DSM-5'E GÖRE CINSEL ORGANLARDA- PELVISTE AĞRI/IÇE GIRME BOZUKLUĞU TANI ÖLÇÜTLERI}

A. Aşağıdakilerden birinde (ya da daha çoğunda), sürekli ya da yineleyici güçlük çekme: 
1. Birleşme sırasında vajinaya girme.

2. Vajinaya girme ya da girme girişimleri sırasında vulvovajinada ya da pelviste belirgin ağrı duyma.

3. Vajinaya girme eyleminin gerçekleşeceği beklenirken ya da vajinaya girme sırasında ya da girilmesinden ötürü, vulvovajinada ya da pelviste ağrı duymayla ilgili olarak belirgin bir korku ya da kaygı duyma.

4. Vajinaya girme girişimi sırasında pelvis tabanı kaslarını çok germe ya da sıkma.

B. A tanı ölçütlerindeki belirtiler, en az, yaklaşık altı aydır sürmektedir.

C. A tanı ölçütlerindeki belirtiler, kişide, klinik açıdan belirgin bir sıkıntıya neden olur.

D. Bu cinsel işlev bozukluğu, cinsel kökenli olmayan bir ruhsal bozuklukla daha iyi açıklanamaz ya da ağır bir ilişki bozukluğundan (örn. eşin kaba güç kullanması) ya da gerginlik yaratıcı önemli başka etkenlerden kaynaklanmamaktadır ve bir maddeye/ilaca ya da başka bir sağlık durumuna bağlanamaz.

Olup olmadığını belirtiniz:

Yaşam boyu: $\mathrm{Bu}$ bozukluk, kişi cinsel açıdan etkin olduğundan beri vardır.

Edinsel: Bu bozukluk, oldukça olağan bir cinsel işlevsellik evresinden sonra başlamıştır.

O sıradaki ağırlı̆̆ını belirtiniz:

Ağır olmayan: A tanı ölçütlerindeki belirtiler en az sıkıntı doğurur.

Orta derecede: A tanı ölçütündeki belirtiler orta düzeyde bir sıkıntı doğurur.

Ağır: A tanı ölçütündeki belirtiler çok sıkıntı doğurur. ${ }^{[9]}$

\section{DÜNYA'DA VE TÜRKIYE'DE VAJINISMUS PREVELANSI}

Dünya'da vajinismus prevalans ve insidansının belirsiz olduğu belirtilirken son zamanlarda literatürde konuyla ilgili önemli veriler yer almaktadır. ${ }^{[16,17]}$

Nobre ve ark. (2006) yaptıkları çalışmada vajinismusun görülme sıklığını \%25,5 olarak belirtilmişlerdir. ${ }^{[18]}$ Birinci basamak temelli bir çalışmada vajinismus oranı \%30 olarak belirtilmiştir. ${ }^{[16]}$ Ter Kuile ve ark.'nın (2009) yaptıkları araştırmada ise birinci basamak sağlık kuruluşlarına, jinekoloji polikliniklerine ve cinsel işlev bozukluğu kliniklerine vajinismus tedavisi için başvuru oranının \%3 ve \%25 arasında değişkenlik gösterdiği belirtilmiştir. ${ }^{[19]}$ Iskandinav ülkelerinde yapılan araştırmalarda ise \%1'in altında olduğu saptanmıştır. ${ }^{[20,21]}$ Konuyla ilgili olarak ülkemizde ise Cinsel Eğitim Tedavi ve Araştırma Derneği (CETAD), vajinismus oranının batı ülkelerine kıyasla \%50 gibi yüksek bir oran olduğu, bu oranın batı ülkelerinde sadece \%10 civarında olduğu belirtilmiştir. ${ }^{[7]}$ Bununla birlikte ülkemizde primer vajinismusun ön planda olduğu vurgulanmıştır. ${ }^{[2,23]}$ Ülkemizde yapılan bir başka çalışmada ise cinsel terapi alan çiftler arasında en sık görülen cinsel işlev bozukluğunun \%15,3 ile en fazla vajinismus olduğu belirlenmiştir. ${ }^{[24]}$ Bir başka çalışmada cinsel işlev bozuklukları kapsamında tedavi amacıyla psikiyatri kliniklerine başvuran kadınların \%73'ünün, polikliniklere başvuran kadınların \%66-75,9'unun ve cinsel işlev bozuklukları polikliniklerine başvuran kadın hastaların \%41'inin vajinismus sorunu

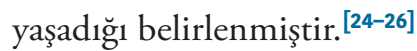

\section{VAJINISMUS NEDENLERI VE ILIȘKILi FAKTÖRLER}

Birey içinde yaşadığ likleri ile gelişimini sürdürürken, bir önceki nesilden doğrudan aktarılan birçok bilginin de etkisi altında kalmaktadır. Doğumdan itibaren sosyal çevre ve toplum, kadın ve erkeğe cinsiyet rolleri konusunda mesajlar vermekte ve toplumsal beklentilere dair kalıplar sunmaktadır. Aktarılan bu bilgiler bazı durumlarda eksik, yanlış, abartılı veya çarpıtılmış olabilmektedir. Cinselliğin, cinse dair konuların rahatlıkla ifade edilemediği toplumlarda cinsellikle ilgili bilgilerin yansımalarını fikralar, espriler, söylemler, medya araçları ve pornografik yayınlarda görülmektedir. Yetersizlik zeminindeki bu bilgilerinde kadınlarda cinsel işlev bozuklukları gelişimi için uygun bir zemin oluşturduğu belirtilmektedir. ${ }^{[27]}$ Vajinismus gelişim nedenleri konusunda birçok çalışma olmasına rağmen uzmanlar arasında bir fikir birliğine ulaşılamamıştır. Birçok uzman vajinismusun psikolojik, sosyal, kültürel, fiziksel faktörler ile ilişkili sorunların bir sonucu olarak geliştiğini vurgulamaktadır. ${ }^{[15,28,29]}$ Daha az olmakla birlikte bazı kaynaklarda ise vajinismusun organik faktörlere bağlı geliştiğine dikkat çekilmektedir. Bu kapsamda enfeksiyonlar, vajinal cerrahi işlemler, kızlık zarı anomalileri, cinsel yolla bulaşan hastalıklar gibi organik faktörler yer almaktadır. ${ }^{[30]}$

Korku ve anksiyeteyi hafifletmek amacıyla aşamalı maruz bırakma, kaçınma davranışını azaltma, gevşeme egzersizi gibi yöntemlerden sonra kadınların büyük bir bölümünün başarılı bir biçimde cinsel ilişki gerçekleştirmesi sonucu bu durumun ortaya çıkmasında korku ve anksiyetenin önemini ön plana çıkarmaktadır. ${ }^{[17,31]}$ Oktay ve Tombul'un (2003) 200 vajinismus tanılı grupta kadınların \%57’sinin ağrı ve aşırı acı duyma korkusu yaşadığı, \%31’inin aşırı kanama 
korkusu yaşadığı, \%18'inin yırtılma/parçalanma korkusu yaşadığı, \%17'sinin penisin içeride kalması korkusu yaşadığı, \%11'inin bayılma korkusu yaşadığı ve \%9'unun tiksinme duygusu yaşadığı belirlenmiştir. Dikkat çeken bulgu kadınların \%18'inin ilk birliktelikte aşırı acı hissettiklerini bildirmelerine karşılık, \%57’sinin ağrı ve acı hissetme korkusu yaşadıklarını ifade etmeleri olmuştur. ${ }^{[22]}$ Vajinismus ile ilişkili diğer faktörler arasında cinsel istismar gibi travmatik cinsel deneyimler, düşük benlik saygısı ve beden imajı, cinsellik hakkında olumsuz tutumlar, cinsiyet hakkında bilgi eksikliği gibi nedenler sayılmaktadır. ${ }^{[32]}$ Bununla birlikte hamile kalma ve doğum korkusu, cinsel tiksintiler, çiftlerin arasında güvensizlik, kadının eşinin cinselliğini bilmemesi, eşlerin birbirlerine karşı aşırı sert ve saldırgan bir tutum içinde olması vajinismus gelişiminde ve kronikleşmesinde etkili faktörler arasında sayılmaktadır. ${ }^{[27,33,34]}$

\section{VAJINIMUS TANI VE TEDAVISI}

Kadınlar vajinismusla karşılaştıklarında bu durumu organik bir kadın hastalı̆̆ı olarak ele alıp öncelikle jinekoloji uzmanlarına başvurmaktadırlar. ${ }^{[35]}$ Jinekoloji uzmanına başvuran ve genellikle vajinismus olduğunun farkına varmayan kadınların tanısı jinekolojik muayeneye ile konulmaktadır. Buna rağmen kadınların genellikle jinekolojik muayeneden çeşitli bahaneler öne sürerek kaçındıkları ya da muayene sırasında şiddetli reaksiyon gösterdikleri ve bu nedenle de muayenelerinin yapılamadığı ya da büyük sıkıntı yaşadıkları belirtilmektedir. ${ }^{[36]} \mathrm{Bu}$ nedenle kadın cinsel bozukluklardan biri olan vajinismusun tanı ve tedavisi multidisipliner yaklaşım içerisinde yürütülmelidir. Ekipte ebeler ile birlikte hemşireler, kadın-doğum uzmanları, ürologlar, psikologlar ve psikiyatrist yer almalıdır Kadınlara cinsel sağlığı ile ilgili değerlendirmeler fiziksel, psikolojik ve sosyokültürel parametreleri kapsamalıdır. Bu kapsamda dikkatli ve detaylı bir klinik öykü alımı ile süreç başlatılmalıdır. ${ }^{[37,38]}$ Vajinismus tanılı kadınların tedavisine farklı tedavi yöntemleri uygulanmaktadır. Bu tedaviler arasında dilatör kullanımı, cinsel danışmanlık, psikoterapi, hipnoterapi ve bilişsel davranışçı terapi yer almaktadır. ${ }^{[39]}$ Vajinismus tedavisinde dilatör kullanımı ile ilgili randomize kontrollü çalışma olmamasına karşın birçok klinisyen dilatör kullanımının vajinismus tedavisinde dilatasyonun sağlanması ile birlikte psikolojik olarak penetrasyon kaygısının üstesinden gelmede yardımc1 olduğu konusunda görüş birliği içindedir. ${ }^{[40,41]}$ Kademeli olarak kullanılan dilatörlerin boyutları büyüdükçe vajinanın gerilmesine yardımcı olmakta ve kadının vajinal penetrasyon sırasında rahatlamasına zemin sağlamaktadır. Ancak çoğu kadın dilatörleri nasıl kullanacağını bilmediği uygulama başarısızlıkla sonuçlanabilmektedir. ${ }^{[39]}$ Bu kapsamda dilatörlerin kullanımı ile ilgili kadına eğitim danışmanlık verilmesi sorunların önemli bir bölümün aşılmasına katkı sağlayacaktır. ${ }^{[42]}$ Vajinal dilatasyon dışında cinsel danışmanlık, çift olarak tedavi olan bireylerin aralarındaki iletişim becerilerini geliştirmelerine yardımcı olurken, kaygıyı azaltma ve libidoyu yükseltme konusunda katkı sağlamaktadır. Vajinismus tedavisi sürecinde cinsel yaşamı tehlikeye giren çiftlere tedavi süresince veya tedavi sonrası cinsel danışmanlık verilmesi çiftlere bu süreçten yararlanmasını olumlu yönde etkileme ve çifter üst düzeyde yarar sağlamaktadır. ${ }^{[43]}$ Diğger tedavi ve destek yöntemleri arasında yer alan psikoterapi ve hipnoterapinin vajinismus tedavisine etkisi benzer şekilde kaygının azaltılmasında etkilidir ve özellikle cinsel istismar öyküsü olan kadınlarda etkili olduğu bilinmektedir. Bununla birlikte Bilişsel Davranışsal Terapi de (BDT) hastaların davranışlarını etkileyen düşünce ve duyguları anlamalarına ve penetrasyon öncesi ve sırasında kaçınma davranışlarını değiştirmelerine yardımcı olmaktadır. ${ }^{[4]}$

\section{VAJINIMUS TANILI KADINLARDA EBELIK YAKLAȘIMI}

Ebeler, kadının cinsel sağlı̆̆ı kapsamında sorunları belirleme, uygun girişimler ile sorunu çözme ve sürdürmede multidisipliner bir ekip içerisinde görev almaktadır. Uluslararası Ebeler Konfederasyonu (ICM) ebelik uygulaması için 2018 yılında yayınladığı temel yetkinlikleri arasında cinsellikle ilgili sağlık sorunlarının tanımlanması, danışmanlık verilmesi ve tedavi edilmesi için danışmanlık verilmesinde yetkinliği olduğunu tanımlamıştır. ${ }^{[45]}$ Buna rağmen cinsel danışmanlık gereksinimi olan hastaların tanımlanmasında birçok sağlık çalışanı istenilen yeterlilikte değildir. ${ }^{[46]}$ Kadınlar arasında cinsel danışmanlık talep etmek ve almak yetersizdir. Bu nedenle özellikle geleneksel toplumlarda birçok kadın gerdek gecesi, ilk cinsel deneyime ilişkin ciddi kaygılar yaşamaktadır. Bu konuda kadınların sağlık eğitimi programları ile bilgilendirilmesi, danışmanlık hizmeti sunulması ve kaygı düzeylerinin azaltılmasında ebelere önemli görev ve sorumluluk düşmektedir. Kadınlar toplumsal olarak birçok negatif yüklü mesajlar ile cinsel ilişkinin, ilk gece acılı ve ağrılı olduğunu hatta kızlık zarının yırtılması ile ciddi kanamanın yaşanacağına dair ifadeler ile duymaktadır. Bu mesajlar doğal olarak kadınlarda kaygı ve korkuya neden olmaktadır. ${ }^{[47,48]}$

Kadın doğum servisleri, kadın doğum poliklinikleri, yenidoğan servisleri, aile planlaması birimleri, gebe eğitim merkezleri, aile sağlığı merkezleri gibi birçok farklı birimde görev alan, birinci ve ikinci basamak sağllk hizmetleri kapsamında her yaştan kadına ulaşma olanağı olan ebelerin vajinismus tanılı, vajinismus sorunu yaşayan kadınların desteklenmesi konusundaki rol ve sorumlulukları şöyle sıralanmaktadır: 
- Kadın cinsel sağlığı konusunda bilinç oluşturmak amacryla bu konuda sağlık eğitim programları yürütülmesi

- Kadınların cinselliğe ilişkin soru sorması yönünde teşvik edilmesi bu amaçla güvenli, uygun ortam oluşturulması

- Genel kadın sağlığı kapsamında değerlendirme yaparken kadın cinselliğe dair soruların ayrıntılı değerlendirilmesi

- Bu yaklaşım içinde cinsel sağlığın güçlendirilmesi için kadının bu konudaki gereksinimlerinin belirlenmesi

- Kadınların cinsel sorunlarını açıklayabilmeleri için uygun iletişim tekniklerini kullanmaları yönünde cesaretlendirilmesi, cinsel sorunların nedenlerini ve özelliklerini belirlemesi

- Hekim ile iş birliği içinde kadınların cinsel fonksiyon durumlarını değerlendirilmeli ve cinsel yaşama ilişkin sorunları belirlemeye yönelik girişimlerde bulunulması

- Vajinismus için başvuran kadınlara hekim tarafından yapılan jinekolojik muayene esnasında kadın ile olumlu iletişim kurarak, muayene süresince basınç, soğukluk hissi, ağrı duyabileceği konusunda bilgilendirerek, uygulanan işlemler ve durumu hakkında bilgi vererek, kullanılan aletleri uygularken nazik olarak, saygilı davranarak utanma duygusunun ve korkusunun azalmasını sağlamak ve hastayı rahatlatabilmek. ${ }^{[25]}$

- Belirlenen sorunların çözümü için bireye ve soruna özgü bir yaklaşımla, uygun girişimlerde bulunulmalı ve kadınların yaşam kalitesi yükseltilmelidir. ${ }^{[45,49,50]}$

- Vajinismus tanısı almış kadınların sorunlarını paylaşabilecekleri ortamın oluşturulması

- Tedavi sürecinin sürekliliği konusunda kadının desteklenmesi (İlaç uyumu, Terapi uyumu vb.). ${ }^{[45]}$

\section{SONUÇ}

Ülkemiz gibi geleneksel toplumlarda cinsellikle ilgili birçok konu hala tabu olma özelliğini korumaktadır. Bu sınırlılık, sınırlamalar psikolojik, sosyal baskıyı beraberinde getirmektedir. Kadının cinsel yaşamı bundan doğrudan etkilenmektedir. Ülkemizde en yaygın görülen kadın cinsel işlev bozukluklarından biri olan vajinismusta bu durumlardan bağımsız değildir. Cinsel eğitimin aile içinde verilmemesi, toplumdaki yanlış inançlarında genç kızların, kadınların cinsel konularda bilgisiz ve deneyimsizliğin de etkili olduğu düşünülmektedir. Ülkemizde tamamı kadınlardan oluşan ebelik profesyonelleri kadın cinsel sağlığı sorunlarının erken dönemde belirlenmesi, vajinismus gibi tanı konmuş durumlarda tedavi sürecinin yönetimi ve desteklenmesinde, sağlık eğitimi, danışmanlık, vaka yönetimi gibi rolleri ile önemli katkı sunacağı, tedavi başarının ve kadın yaşam kalitesinin yükseltilmesinde etkili olacağı düşünülmektedir. Bu konuda etkin çalışmalar yürütebilmek için ebelerin kadın cinsel sağlığı sorunları, tanı tedavisi ve profesyonel ebelik yaklaşımı konusunda donanımlı olmaları büyük önem taşımaktadır. Eğitim sürecinde ve mezuniyet sonrasında sürekli eğitim programları ve bilimsel platformlarda ebe grubuna yönelik kadın cinsel sağlığı eğitim programlarının yürütülmesinin farkındalık gelişiminde önemli katkı sağlayacak düşünülmektedir.

\section{Hakem Değerlendirmesi}

Dış bağımsız

Çıkar Çatışması

Yazarlar çıkar ilişkisi olmadığını beyan etmişlerdir.

Finansal Destek

Herhangi bir mali destek alınmamıştır.

\section{Peer-review}

Externally peer-reviewed.

Conflict of Interest

No conflict of interest was declared by the authors.

Financial Disclosure

No financial disclosure was received.

\section{KAYNAKLAR}

1. World Health Organization (WHO). Defining Sexual Health Report of a Technical Consultation on Sexual Health; 2006. https://www.who.int/reproductivehealth/publications/sexual_ health/defining_sh/en/

2. Mehdizadeh Toorzani Z, Zahraei RH, Ehsanpour S, Nasiri M, Shahidi S, Soleimani B. A study on the relationship of sexual satisfaction and common contraceptive methods employed by the couples. Iran J Nurs Midwifery Res 2010;5:115-9. https://www. ncbi.nlm.nih.gov/pmc/articles/PMC3093165/

3. Hassan RS, Eraky EM, Abou Khatwa AM, Ghonemy GI. Study the effect of hormonal contraceptive methods on female sexual function. Med J Cairo Univ 2015;83:115-20. http://www. medicaljournalofcairouniversity.net/images/pdf/2015/march/58.pdf

4. Hamadiyan H, Oladi MAG, Rahbar P, Azad M. Prevalence of sexual dysfunction among women using contraceptive methods. Int J Med Res Health Sci 2016;5:163-7. https://www.ijmrhs. $\mathrm{com} / \mathrm{medical}$-research/prevalence-of-sexual-dysfunction-amongwomen-using-contraceptive-methods.pdf

5. First MB, Wakefield JC. Diagnostic criteria as dysfunction indicators: bridging the chasm between the definition of mental disorder and diagnostic criteria for specific disorders. Can J Psychiatry 2013;58:663-9. [CrossRef]

6. Oksuz E, Malhan S. Prevalence and risk factors for female sexual dysfunction in Turkish women. J Urol 2006;175:654-8. [CrossRef]

7. Yüksel Ş, Cindoğlu D, editörler. CETAD Cinsel Sağlık ve Üreme Sağlığı Alanında Ulusal ve Yerel Medya Yoluyla Savunuculuk Projesi, Bilgilendirme Dosyası 5: Kadın Cinselliği; 2006. https:// www.cetad.org.tr/etkinlikler/75/kongreler/10/cinsel-saglik-veureme-sagligi-alaninda-ulusal-ve-yerel-medya-yoluyla-savunuculu

8. American Psychiatric Association. Diagnostic criteria from DSMIV-TR. American Psychiatric Publications; 2000.

9. American Psychiatric Association. Diagnostic and statistical manual of mental disorders (DSM-5 ${ }^{\oplus}$. American Psychiatric Publications; 2013.

10. Sims MJ. On Vaginismus. Trans Obstet Soc London 1861;3:35667. 
11. Donath T. Anatomical Dictionary with Nomenclatures. Elsevier Publishing; 1969.

12. Gürdal A. Psikanalizde Kadınlık Üzerine İlk Görüşler; Psikanaliz Yazıları. İstanbul: Bağlam Yayıncılık; 2011. s.2.

13. Zargooshi J. Unconsummated marriage: clarification of etiology; treatment with intracorporeal injection. BJU Int 2000;86:77-9. [CrossRef]

14. McGuire H, Hawton K. Interventions for vaginismus. Cochrane Database Syst Rev 2001;1:CD001760. [CrossRef]

15. Hope ME, Farmer L, McAllister KF, Cumming GP. Vaginismus in peri and postmenopausal women: a pragmatic approach for general practitioners and gynaecologists. Menopause Int 2010;16:68-73. [CrossRef]

16. Oniz A, Keskinoglu P, Bezircioglu I. The prevalence and causes of sexual problems among premenopausal Turkish women. J Sex Med 2007;4:1575-81. [CrossRef]

17. Maseroli E, Scavello I, Rastrelli G, Limoncin E, Cipriani S, Corona $\mathrm{G}$, et al. Outcome of medical and psychosexual interventions for vaginismus: a systematic review and meta-analysis. J Sex Med 2018;15:1752-64. [CrossRef]

18. Nobre PJ, Pinto-Gouveia JE, Gomes FA. Prevalence and Comorbidity of Sexual Dysfunctions in a Portuguese Clinical Sample. J Sex Marital Ther 2006;32:173-82. [CrossRef]

19. Ter Kuile MM, Bulté I, Weijenborg P, Beekman A, Melles R, Onghena P. Therapist-Aided Exposure For Women With Lifelong Vaginismus: A Replicated Single-Case Design. J Consult Clin Psychol 2009;77:149-59. [CrossRef]

20. Engman M. Partial vaginismus definition, symptoms and treatment. Linköping University Medical Dissertation; 2007. http://vestibulit. se/wp-content/uploads/2017/09/FULLTEXT01-1.pdf

21. Christensen BS, Gronbaek M, Osler M, Pedersen BV, Graugaard C, Frisch M. Sexual dysfunction and difficulties in Denmark: prevalence and associated sociodemographic factors. Arch Sex Behav 2011;40:121-32. [CrossRef]

22. Oktay M, Tombul K. 200 Vajinismus vak'ası ve eşlerinin psikolojik yönden incelenmesi. Yeni Symposium 2003;41:115-9.

23. Berkol TD, Uzun I, Alataş E, Erensoy H, Özyıldırım İ. Birincil Tanısı Majör Depresif Bozukluk veya Anksiyete Bozukluğu Olan Cinsel Yönden Aktif Kadınlardaki Vajinismus Komorbiditesi. Med J Bakirkoy 2015;11:150-3. [CrossRef]

24. Yılmaz E, Zeytinci İE, Sarı S, Karababa İF, Çilli AS, Kuçur R. Konya il merkezinde yaşayan evli nüfusta cinsel sorunların araştırılması. Turk J Psychiatry 2010;21:126-34. http://www. turkpsikiyatri.com/PDF/C21S2/126-134.pdf

25. Doğan S, Varol Saraçoğlu G. Yaşam boyu vajinismusu olan kadınlarda cinsel bilgi, evlilik özellikleri, cinsel işlev ve doyumun değerlendirilmesi. Trakya Univ Tip Fak Derg 2009;26:151-8.

26. Yıldırım EA, Akyüz F, Hacıoğlu M, Eşsizoğlu A, Çoşut Çakmak A, Çakmak E, Erdiman S. Cinsel İşlev Bozuklukları Kliniğine Başvuran Olgularda Başvuru Yakınması ile Klinik Tanı Arasındaki İlişki. Nöropsikiyatri Arşivi 2011;48:24-30. [CrossRef]

27. Ersanlı K, Kumcağı H. Cinsel Sağlı Eğitimi. Ankara: Pegem Akademi; 2016. https://www.pegem.net/dosyalar/ dokuman/24112016101153pdf.pdf

28. Wijma B, Engman M, Wijma K. A model for critical review of literature - with vaginismus as an example. J Psychosom Obstet Gynaecol 2007;28:21-36. [CrossRef]

29. Pacik PT, Geletta S. Vaginismus treatment: clinical trials follow up 241 patients. Sex Med 2017;5:E114-23. [CrossRef]

30. Jeng CJ. The pathophysiology and etiology of vaginismus. Taiwanese J Obstet Gynecol 2004;43:10-5. [CrossRef]
31. Ter Kuile MM, Van Lankveld JJ, De Groot E, Melles R, Neffs J, Zandbergen M. Cognitive-behavioral therapy for women with lifelong vaginismus: process and prognostic factors. Behav Res Ther 2007;45:359-73. [CrossRef]

32. Nobre PJ, Pinto-Gouveia J. Cognitive and emotional predictors of female sexual dysfunctions: preliminary findings. J Sex Marital Ther 2008;34:325-42. [CrossRef]

33. Karagüzel EÖ, Arslan FC, Tiryaki A, Osmanağaoğlu MA, Kaygusuz EŞ. Sociodemographic features, depression and anxiety in women with life-long vaginismus. Alpha Psychiatry 2016;17:489-95. [CrossRef]

34. Zgueb Y, Ouali U, Achour R, Jomli R, Nacef F. Cultural aspects of vaginismus therapy: a case series of Arab-Muslim patients. Cogn Behav Ther 2019;12:e3. [CrossRef]

35. Çuhadaroğlu F, Dünya Sağlık Örgütü. ICD-10 Ruhsal ve Davranışsal Bozukluklar Sınıflandırması Klinik Tanımlamalar ve Tanı Kılavuzları. Ankara: Türkiye Sinir ve Ruh Sağlığı Derneği Yayını; 1993.

36. Armutçu E. Türkiye Cinselliğini Konuşuyor. İstanbul: Doğan Kitapçllı; 2006.

37. Crowley T, Richardson D, Goldmeier D; Bashh Special Interest Group for Sexual Dysfunction. Recommendations for the management of vaginismus: BASHH Special Interest Group for Sexual Dysfunction. Int J STD AIDS 2006;17:14-8. [CrossRef]

38. Mete S. Kadın ve cinsellik. İçinde: Şirin A, Kavlak O, editörler. Kadın Sağlığı. I. Baskı. İzmir: Bedray Yayıncılık; 2008.

39. Pacik PT. Understanding and treating vaginismus: a multimodal approach. Int Urogynecol J 2014;25:1613-20. [CrossRef]

40. Pacik PT. Vaginismus: review of current concepts and treat- ment using Botox injections, bupivacaine injections, and progressive dilation with the patient under anesthesia. Aesthet Plast Surg 2011;35:1160-4. [CrossRef]

41. Aslan M, Yavuzkır Ş, Baykara S. Is "Dilator Use" More Effective Than "Finger Use" in Exposure Therapy in Vaginismus Treatment? J Sex Marital Ther 2020;46:354-60. [CrossRef]

42. Pacik PT, Cole JB, Piar N. When Sex Seems İmpossible: Stories of Vaginismus \& How You Can Achieve Intimacy. Odyne Publishing; 2010.

43. Bergeron S, Meana M, Yitzchak B, Khalife S. Painful sex. In: Levine SB, editor. Handbook of Clinical Sexuality for Mental Health Professionals, 2nd ed. New York: Routledge; 2010. p.193-214.

44. Engman M, Wijma K, Wijma B. Long-term coital behaviour in women treated with cognitive behaviour therapy for superficial coital pain and vaginismus. Cogn Behav Ther 2010;39:193-202. [CrossRef]

45. International Confederation of Midwives. Essential Competencies for Midwifery Practice Update 2018. https:// www.internationalmidwives.org/assets/files/general-files/2019/03/ poster-icm-competencies-en-screens.pdf

46. Khadivzadeh T, Ardaghi M, Mirzaii K, Mazloum SR. The effect of interactive educational workshops with or without standardized patients on the self-efficacy of midwifery students in sexual health counseling. J Midwifery Reprod Health 2016;4:562-70. [CrossRef]

47. Soygüt GB. Kadın cinsel işlev bozuklukları. Psikiyatri Dünyası 1999;2:54-9.

48. T.C. Sağlık Bakanlığı Ana Çocuk Sağlığı ve Aile Planlaması Genel Müdürlüğü. Ulusal Aile Planlaması Hizmet Rehberi. Aile Planlaması ve Üreme Sağlığı, Cilt 1. Ankara: Damla Matbaacılık; 2005. http://www.istanbulsaglik.gov.tr/w/sb/halksag/belge/ mevzuat/ulusaile_plan_hizmet_rehberi1_cilt.pdf

49. Alexander LL, Larosa JH, Bader H, Garfield S. New Dimensions in Women's Health, 4th ed. Jones and Bartlett Publishers; 2007. p.121.

50. Kütmeç C. Kadınlarda cinsel fonksiyon bozukluğu ve hemşirelik bakımı. Fırat Sağlık Hizmetleri Derg 2009;4:111-36. 